\section{Going the extra mile on reception}

A dental receptionist from Plymouth has won the British Dental Receptionist Association's Extra Mile Award. The award was sponsored by Vital magazine, The Dental Resource Company and DenMed. It was presented to Deborah Hutchinson from the Crescent Speciality Dental Centre by Stephen Hancocks OBE, Editor-in-Chief of the British Dental Journal and Vital, at the British Dental Conference and Exhibition in Birmingham earlier this year, together with a Red Letter Day voucher.

The Extra Mile Award began in 2005 and each of the judges was equally impressed with Deborah, who was nominated by her employer Jeremy Peak. He said: 'Deborah is worthy of the award because of her absolute dedication to hands-on teamwork. In addition to engrossing herself in finding out about what happens in the treatment rooms in her own time, she has undertaken the

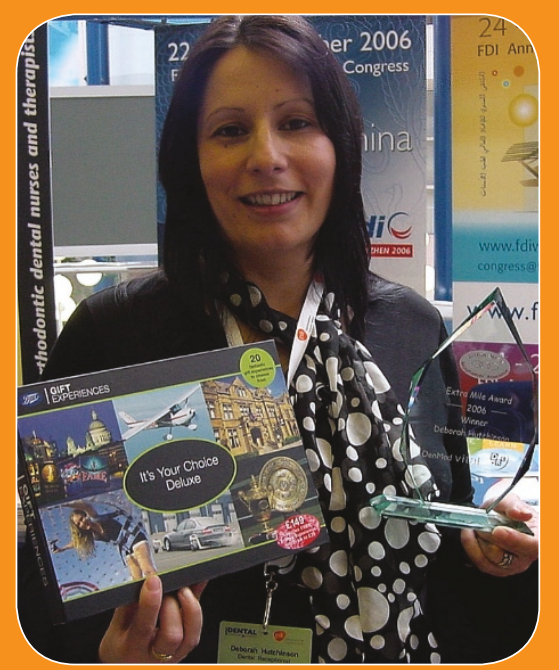

training of new staff and created a reception manual to ensure consistent reception services for patients and her colleagues in the dental team.'

\title{
Complaints \\ service launched
}

A new impartial service to resolve complaints about private dental care has been launched by the General Dental Council in order to help resolve such complaints as fairly and quickly as possible.

The Dental Complaints Service will cover the whole of the UK and will be open to patients wishing to complain about any aspect of dental care, treatment or service involving any member of a dental team. Currently, NHS dental patients can use the NHS complaints process, but private patients who have not been able to resolve their complaint with a dental practice have limited options open to them. The new service seeks to fill that gap.

Dissatisfied dental patients who call the Dental Complaints Service will first be encouraged to use their dental practice's own complaints procedures, if they have not already done so. If a complaint remains unresolved, Dental Complaints Service advisers will discuss it directly with the patient and dental professional concerned.

If the adviser cannot resolve matters, the complaint will go to one of a series of regional panels. The panel will meet with the dentist and complainant and recommend how best to resolve the complaint. Their emphasis will be on resolving complaints using common sense.

Serious complaints - which raise issues about patient safety and whether a practitioner should be allowed to continue practising - will continue to be dealt with by the GDC as they are now.

The Dental Complaints Service is preparing for around 2-4,000 complaints a year from across the UK. It is hoped that around $80 \%$ of these complaints will be resolved by
DCPs receive Queen's binthalay homours

Individuals from the dental team featured heavily in the Queen's birthday honours list this year. Recipients of MBEs included Sara Holmes, Head of the School of Dental Care Professionals at the University of Portsmouth; Derek Miles, the Chief Dental Equipment Technician at the University of Cardiff Dental School; and Warrant Officer Class 2 Elizabeth Deuchers, a dental hygienist of the Royal Army Dental Corps, for her outstanding contribution to the education of Dental Care Professionals and her work with the charity Crisis at Christmas.

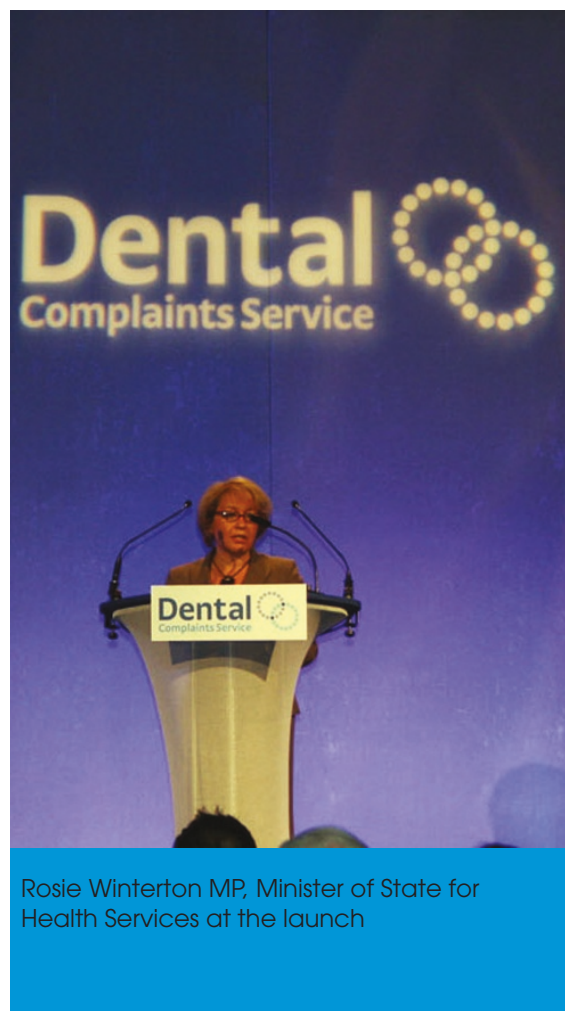

advisers, without the need to hold a panel.

For more information visit www.dentalcomplaints.org.uk. 